\title{
Spastic paraplegia-glaucoma-intellectual disability syndrome
}

INSERM

\section{Source}

INSERM. (1999). Orphanet: an online rare disease and orphan drug data base. Spastic paraplegia-glaucoma-intellectual disability syndrome. ORPHA:2818

Spastic paraplegia-glaucoma-intellectual disability syndrome is characterized by progressive spastic paraplegia, glaucoma and intellectual deficit. It has been described in two families. The second described sibship was born to consanguineous parents. The mode of inheritance is autosomal recessive. 